\title{
La agricultura familiar y la economía solidaria: avance de investigación
}

\author{
Willian Torrente-Castro*, Jarrison Martínez ${ }^{\star *}$
}

\begin{abstract}
Resumen
Este artículo presenta los resultados de la investigación enmarcada en la celebración del Año Internacional de la Agricultura Familiar 2014, para el caso específico de la Asociación de Mujeres Cafeteras del municipio de La Plata, Huila. Se visibilizan los múltiples aportes de la agricultura familiar en Colombia, así como se resaltan sus potencialidades para hacer frente a los retos de la agricultura y la alimentación en el país, que se potencializan cuando son tratados a través de una organización social y solidaria. La investigación permite evidenciar cómo en los sistemas de finca en los que se desarrolla la agricultura familiar se cumple con las siguientes características: tenencia lícita de la tierra; contratación de mano de obra en épocas de cosecha (de resto se utiliza la mano de obra familiar); el sistema de producción mezcla el tradicional con el innovador o técnico; existe preocupación por la conservación de los suelos y del medio ambiente; tienen un producto comercial como eje económico, y desarrollan a la par otros sistemas productivos destinados al autoconsumo o al mercado; la multifuncionalidad los hace requerir de varias fuentes de recursos a la vez, entre otras. Asimismo, cuando se identifican necesidades comunes y existe compromiso por su satisfacción, se genera conciencia de que la agricultura familiar es una gran riqueza para los hogares. Sin embargo, se hace más visible el trabajo cuando se contribuye al desarrollo de cada una de las familias y comunidades a través de la asociatividad social y solidaria.
\end{abstract}

Palabras clave: agricultura familiar, asociatividad, economía solidaria, multifuncionalidad.

\section{Family Farming and the Solidarity Economy: Advances in Research}

\begin{abstract}
This article presents the results of research that was part of the celebration of the International Year of Family Farming in 2014, in the specific case of the Association of Women Coffee Growers (Asociación de Mujeres Cafeteras) in the municipality of La Plata, Huila. The article shows the many contributions of family farming in Colombia, while stressing its potential to face the challenges of agriculture and food in the country, which can be boosted when dealt with through a social and solidarity organization. The research shows how family farming systems fulfil the following characteristics: legal landholding, hiring of labor at harvest times (the rest of the time they use family labor), the production system mixes the traditional with the innovative or technical, there is concern over soil conservation and environmental preservation, they have a commercial product as their economic backbone and simultaneously develop other productive systems for self-consumption and/or the market, also because multi-functionality requires them to have simultaneous access to multiple sources of resources, among others. Also, when shared needs are identified and there is a commitment to satisfy them, awareness is generated that family farming signifies great wealth for households. However, the work becomes more visible when there is a contribution to the development of each family and community through social and solidarity associativity.
\end{abstract}

Keywords: family farming, associativity, solidarity economy, multi-functionality.

\section{A agricultura familiar e a economia solidária: progresso de pesquisa}

\section{Resumo}

Este artigo apresenta os resultados da pesquisa delimitada na celebração do Ano Internacional da Agricultura Familiar 2014, para o caso específico da Associação de Mulheres Cafeeiras do município de La Plata (Huila, Colômbia). Visibilizam-se as múltiplas contribuições da agricultura familiar na Colômbia, bem como se ressaltam suas potencialidades para enfrentar os desafios da agricultura e da alimentação no país, que se potencializam quando são tratados por meio de uma organização social e solidária. A pesquisa permite evidenciar como nos sistemas de fazendas nas quais se desenvolve a agricultura familiar são cumpridas as seguintes características: apropriação lícita da terra, contratação de mão de obra em época de colheita (em outros períodos, utiliza-se mão de obra familiar), o sistema de produção mistura o tradicional com o inovador ou técnico, existe preocupação pela preservação dos solos e do meio ambiente, têm um produto comercial como eixo econômico, e desenvolvem paralelamente a outros sistemas produtivos destinados ao autoconsumo e/ou ao mercado, assim como o fato de a multifuncionalidade fazê-los requerer de várias fontes de recursos ao mesmo tempo, entre outras. Além disso, quando se identificam necessidades comuns e existe compromisso por sua satisfação, gerase consciência de que a agricultura familiar é uma grande riqueza para os lares. Contudo, faz-se mais visível o trabalho quando se contribui para o desenvolvimento de cada uma das famílias e comunidades por meio da associatividade social e solidária.

Palavras-chave: agricultura familiar, associatividade, economia solidária, multifuncionalidade. 


\section{Introducción}

Según la Asamblea Departamental del Huila (2013), en este departamento existen dos sistemas de producción agropecuaria bien marcados: el de la economía comercial (de avanzada) y el de la economía de subsistencia (tradicional). El primero oferta para un mercado amplio y bien definido, mientras el de subsistencia está destinado a cubrir las necesidades de consumo doméstico (Caballero, 2013). Esta dualidad también se ve reflejada en cada subregión. Cabe señalar cómo las zonas económicas delineadas en el Huila también se ven identificadas por la forma de explotación agropecuaria predominante. Así, en la zona norte, con epicentro comercial en Neiva, la capital, se observan explotaciones comerciales (arroz, tabaco, piscicultura); en la zona centro, con epicentro en Garzón, hay una especie de transición entre lo comercial y lo tradicional (café, arroz y frutales); en la zona sur, cuyo eje es Pitalito, su agricultura se basa en el café y los frutales; y, finalmente, en la zona occidente, de la cual es epicentro el municipio de La Plata, confluyen, por su característica de eje comercial de la subregión occidente, los habitantes de las poblaciones aledañas con el fin adelantar gestiones de carácter socioeconómicas. En La Plata se concentran las actividades comerciales y financieras de La Argentina, Paicol, Tesalia y Nátaga; su economía se fundamenta en la explotación agrícola y ganadera tradicional, y además del café, son importantes la producción de maíz, fríjol, plátano, cacao, frutales (en especial, lulo, tomate de árbol y mora) y yuca. En el sector pecuario, se destacan la ganadería y la avicultura (tabla 1).

Según el documento de "Revisión y Ajuste del Plan Básico de Ordenamiento Territorial" del municipio de La Plata (Administración Municipal de La Plata, 2005), se establecen una serie de falencias en el sector rural, sobre todo en la producción agropecuaria, lo cual no ha permitido su consolidación. Si esa producción se genera en gran parte por pequeños productores agropecuarios (Diario del Huila, 2013), es lógico inferir que su situación no es la mejor y se requiere de acciones concretas para su fortalecimiento, de manera que lleguen a ser territorios productivos y competitivos que protejan el medio ambiente.

Tales elementos se pueden resumir en: asociatividad no consolidada, producción agropecuaria sin planificación y sin consultar la aptitud de los suelos, y altos niveles de pobreza rural.
Tabla 1

La Plata. Producción agrícola y bovina

\begin{tabular}{lcc}
\hline Cultivos & $\begin{array}{c}\text { Participación en el área } \\
\text { sembrada en ha (2010) }\end{array}$ & $\begin{array}{c}\text { Producción } \\
\text { anual }\left(\mathrm{T}^{*}\right)\end{array}$ \\
\hline Café & 7830 & 6856 \\
Maiz & 2630 & 5722 \\
Frijol & 5140 & 3798 \\
Plátano & 1363 & 4137 \\
Cacao & 250 & 1000 \\
Frutales & 840 & 4200 \\
Yuca & 280 & 2295 \\
Producción bovina & & \\
Sacrificio & 6965 & 2535 \\
Lechero & 4000 & 4113500 lts. \\
Avicola & 0,6 & 320 \\
\hline
\end{tabular}

Nota. Tomado de Plan de Desarrollo 2012-2015: "Unidos por la vía de la prosperidad”, por Alcaldía Municipal La Plata-Huila, 2012. ${ }^{*}$ T: toneladas

La caracterización de la agricultura familiar permite definir acciones en torno a esas deficiencias, de forma que los gobiernos, la academia y el sector privado pueden identificar estrategias para suplir las necesidades de modernización de la producción, transformación y comercialización, sobre todo en lo que tiene que ver con la asociatividad, asistencia técnica, investigación y desarrollo tecnológico, infraestructura, crédito, flujos y canales de comercialización.

\section{Metodología}

El presente estudio de caso hace parte integral de un proyecto de carácter nacional denominado "Análisis de las contribuciones de la agricultura familiar en Colombia desde el enfoque de la multifuncionalidad de la agricultura, MFA" ${ }^{\prime}$, del cual se toma la metodología con el fin de adelantar la investigación. Se emplean herramientas tales como entrevista no estructurada de carácter exploratorio, taller comunitario con grupo focal, observación participante, diario de campo y entrevistas semiestructuradas con los responsables de cada sistema de finca evaluado.

La primera parte del estudio corresponde a la realización de un sondeo con una empresa cooperativa regional, la Cooperativa de Caficultores del Huila

Véase Acevedo (2014) 
(Cadefihuila Ltda.) ${ }^{2}$, con el coordinador de la Unidad de Asistencia Técnica Agroempresarial y de Proyectos (Epsagro), la jefe de oficina de La Plata, y los funcionarios de la Epsagro del mismo municipio. Una vez analizadas las opciones, se tomó la decisión de realizar el estudio con la Asociación de Mujeres de La Plata; luego se adelantó una reunión con las líderes de la organización: nueve representantes de cada una de las veredas en donde tienen asiento las asociadas. Esto dio como resultado la selección de las 27 mujeres a quienes aplicar el objeto de esta investigación, a fin de caracterizar la multifuncionalidad de la agricultura familiar y la incidencia de la asociatividad social y solidaria en esta forma de producción agropecuaria.

Con el propósito de apoyar el trabajo de campo, se recurrió también a información secundaria, referida básicamente a datos sociales y económicos de la región de influencia, los cuales fueron investigados en los proyectos educativos de las instituciones educativas que hacen presencia en la zona de estudio.

La segunda fase incluyó la caracterización de los sistemas de finca, analizando las cinco dimensiones definidas en la metodología:

- Dimensión ambiental: tiene que ver con todos los factores ambientales.

- Dimensión productiva: relacionada con la producción de alimentos, materias primas y servicios, los cuales son usados para el autoconsumo familiar, el intercambio o trueque y el mercado.

- Dimensión económica: se refiere exclusivamente al segmento de la producción o los servicios que están relacionados con el mercado, con el propósito de generar ingresos económicos.

- Dimensión social: relacionada con las condiciones del tejido familiar y comunitario.

- Dimensión cultural: conformada por el conjunto de representaciones sociales o formas comunes de actuar que identifica a un grupo social.

Para la caracterización detallada en cada sistema productivo, se hizo reconocimiento del sistema de finca en campo, diálogo con la familia, agricultoras y líderes de la asociación, insistiendo en las preguntas de

2 La Cooperativa departamental de caficultores del Huila (Cadefihuila) nace en 1963 como iniciativa y respuesta a una necesidad de mercadear el café pergamino seco a los productores del grano del departamento. También como la necesidad de agruparse los pequeños productores en una entidad cooperativa que representara sus intereses. diversas formas para ratificar la coherencia de la información suministrada, acompañados de los técnicos de Cadefihuila Ltda.

La guía para la entrevista semiestructurada empleada en la caracterización fue diseñada a partir de ocho temas, a fin de recopilar información específica referida a los sistemas de finca, así:

- Tema 1. Localización y composición familiar. Incluye nombre de la finca, áreas, localización, edades y escolaridad de los miembros de la familia, tenencia de la tierra.

- Tema 2. Roles por género. Incluye la distribución de labores familiares (productivas o reproductivas) y comunitarias determinando por género quién decide, ejecuta o apoya el desarrollo de las actividades.

- Tema 3. Recursos naturales. Incluye datos de vegetación y fauna silvestres con sus respectivos usos, así como información sobre fuentes de agua.

- Tema 4. Caracterización de lotes del sistema de finca. Incluye área de cada lote y arreglo productivo.

- Tema 5. Producción. Incluye especies agrícolas y variedades cultivadas, producción anual, destino de la producción (autoconsumo o mercado); producción pecuaria, cantidad de animales, producción y destino; producción forestal, usos y destino de los productos; producción agroindustrial, cantidad de productos, destino de la producción. Otras actividades productivas: minería, artesanías, etc.

- Tema 6. Tecnología empleada. Incluye una descripción sobre el empleo de prácticas tradicionales o tecnologías modernas en las siguientes actividades productivas: manejo de suelos, tipo de fertilización, origen de las semillas, manejo de arvenses y manejo de plagas y enfermedades.

- Tema 7. Inversiones y gastos. Incluye empleo de mano de obra familiar y asalariada, uso de maquinaria propia o alquilada, insumos (agroquímicos, naturales u orgánicos), materiales y otros gastos. Para el caso de insumos agroquímicos se estableció tipo, nombre comercial, ingrediente activo y grado de toxicidad.

- Tema 8. Ingresos. Incluye la cuantificación de ingresos por productos agrícolas, pecuarios, forestales, agroindustriales, otros productos y servicios posibles como venta de fuerza laboral y servicios de ecoturismo o alimentación. De igual forma, acceso a crédito, estrategias de mercado directo, mayorista, minorista, contratada, etc. 
Para el análisis de la información obtenida de los 27 sistemas de finca estudiados a profundidad, se recurrió a información cuantitativa como medición (áreas, número de jornales, kilogramos de insumos, etc.), y herramientas de estadística descriptiva (promedios, sumatorias, frecuencias, porcentajes).

\section{Resultados}

\section{Tenencia de la tierra}

De los sistemas de finca estudiados, 20 son propiedad de las mujeres y cuentan con escritura pública; solo una tiene documento de compraventa, y las seis restantes están a la espera de la solución de sucesión para hacer escritura. Es interesante verificar cómo, a partir de la propiedad familiar y ancestral, las mujeres han adquirido su propio terreno para adelantar labores agropecuarias (tabla 2).

Tabla 2

Tenencia de la tierra

\begin{tabular}{lcc}
\hline \multicolumn{1}{c}{ Tenencia } & No. de fincas & $\%$ \\
\hline Propia, con escritura & 20 & 74,1 \\
Propia, con documento & 1 & 3,7 \\
Sucesión ilíquida & 6 & 22,2 \\
\hline TOTAL & $\mathbf{2 7}$ & $\mathbf{1 0 0 , 0}$ \\
\hline
\end{tabular}

Nota. Elaboración propia

\section{Área total de los sistemas de finca}

El 48,15\% de las mujeres (es decir, 13) tiene fincas con áreas que van desde 1 hasta 3 ha. Le siguen en importancia nueve fincas con extensiones que van de 3 a 5 ha; cuatro fincas tienen menos de 1 ha y solo una tiene más de 5 ha (tabla 3). El área de los sistemas de finca da la opción entonces de la multifuncionalidad, utilizando el máximo del terreno para sacar el mejor provecho.

Tabla 3

Área total de las fincas

\begin{tabular}{lcc}
\hline \multicolumn{1}{c}{ Intervalo (HA) } & No. de fincas & $\%$ \\
\hline De 0 a 1 & 4 & 14,81 \\
Más de 1 a 3 & 13 & 48,15 \\
Más de 3 a 5 & 9 & 33,33 \\
Más de 5 & 1 & 3,70 \\
\hline TOTAL & $\mathbf{2 7}$ & $\mathbf{1 0 0 , 0 0}$ \\
\hline
\end{tabular}

Nota. Elaboración propia

\section{Organización social}

Las mujeres cafeteras del occidente del Huila han logrado, luego de un largo camino, con el apoyo de instituciones como el Comité Departamental de Cafeteros, Cadefihuila Ltda. y la Gobernación del Huila, entre otras, constituirse en una asociación que busca potenciar al máximo su labor como líderes en una región con grandes necesidades. Hasta el momento han centrado su fortaleza organizacional en el café como producto básico de su economía. Sin embargo, no desconocen la importancia de otros cultivos y de productos pecuarios, y están incursionando en proyectos de huertas y trabajando por la consolidación de acciones que generen cambios positivos en su calidad de vida.

La Asociación de Mujeres de La Plata es una organización del sector de la economía solidaria, del tipo organización social de desarrollo, y como tal se rige por los principios y fines de la economía solidaria. Esta asociación demuestra las siguientes características:

1. Tienen establecido como vínculo asociativo el mejoramiento integral de la calidad de vida.

2. No tiene ánimo de lucro, es solidaria.

3. Todas sus asociadas tienen equidad en el reconocimiento de sus derechos y cumplimiento de sus deberes.

4. Trabajan cooperadamente para el logro de sus objetivos.

Las mujeres también asumen las decisiones respecto al mantenimiento del hogar, asistencia a los hijos y la representación de la familia en los aspectos relacionados con la educación de los hijos y los de organización social. Es importante resaltar en estos elementos que el trabajo de la mujer en el nivel organizacional no solo se refleja en el fortalecimiento y consolidación de la asociación como representativa ante la sociedad, sino también ejerce marcada influencia en los siguientes aspectos de la vida familiar y comunitaria:

- Inculca el valor cultural, social y económico de la comunidad.

- Integra a la familia al trabajo en equipo.

- Resalta el trabajo de la mujer como parte fundamental en la sociedad.

- El aporte de la mujer en la empresa cafetera concientiza a los esposos acerca de la importancia del trabajo en equidad de género. 
- Conserva la flora y la fauna.

- Mediante el trabajo interinstitucional (Comité de Cafeteros, sena, Cooperativa de Caficultores), se capacita el núcleo familiar en la parte financiera, agrícola y psicológica.

- Contribuye al bienestar de la familia con una alimentación sana.

- Mejoramiento económico del núcleo familiar.

- Produce alimentos de calidad que contribuyen a la alimentación de muchas familias del entorno.

En conclusión, como dice la presidenta de la Asociación, Maussellen Llanos Yasnó, su esfuerzo organizacional les permite

Sin dejar de ser amas de casa, con todo el amor que implica cumplir esta labor, también somos empresarias, líderes con un proyecto de vida definido, con sueños por cumplir pero sobre todo con el convencimiento que hoy podemos aportar mucho de nosotras a nuestras familias, a la comunidad y a la sociedad.

\section{Composición familiar y vinculación a las actividades agropecuarias}

Este estudio relacionó específicamente los miembros de la familia que viven en la finca, obviando a aquellos integrantes que han emigrado a centros poblados, regionales o nacionales(tabla 4 ).

Una vez concluida la educación básica, los jóvenes emigran a centros poblados más grandes, en donde creen encontrar mayores y mejores posibilidades de continuar sus estudios, a la par de tener oportunidades de puestos de trabajo que les permitan su sostenimiento y la posibilidad de colaborar con sus familias. Las poblaciones preferidas son Bogotá, Cali, Popayán, Neiva y el casco urbano de La Plata, en donde también se da la oportunidad de adelantar estudios técnicos, tecnológicos o superiores.

En los sistemas de finca estudiados hay cinco personas en promedio que viven en ellos, de los cuales, cuatro trabajan adelantando labores propias de la finca. Los niños, cuando no están en clase, apoyan algunas labores de baja complejidad.

Tabla 4

Composición familiar

\begin{tabular}{|c|c|c|c|c|c|c|c|c|c|c|}
\hline $\mathrm{N}^{\circ}$ & $\begin{array}{l}\text { Nombre de la } \\
\text { finca }\end{array}$ & $\begin{array}{c}\text { Total } \\
\text { miembros } \\
\text { de la } \\
\text { familia } \\
\text { que viven } \\
\text { en la finca } \\
\end{array}$ & $\begin{array}{l}\text { Miembros } \\
\text { de la } \\
\text { familia } \\
\text { menores } \\
\text { de } 10 \text { años }\end{array}$ & $\begin{array}{c}\text { Miembros } \\
\text { de la } \\
\text { familia } \\
\text { entre 10- } \\
20 \text { años }\end{array}$ & $\begin{array}{c}\text { Miembros } \\
\text { de la } \\
\text { familia } \\
\text { entre } 20- \\
30 \text { años }\end{array}$ & $\begin{array}{l}\text { Miembros } \\
\text { de la } \\
\text { familia } \\
\text { entre } 30 \text { - } \\
40 \text { años }\end{array}$ & $\begin{array}{l}\text { Miembros } \\
\text { de la } \\
\text { familia } \\
\text { entre } 40 \text { - } \\
50 \text { años }\end{array}$ & $\begin{array}{l}\text { Miembros } \\
\text { de la } \\
\text { familia } \\
\text { mayores } \\
\text { de } 50 \text { años }\end{array}$ & $\begin{array}{c}\text { No } \\
\text { miembros } \\
\text { dedicados } \\
\text { a la finca }\end{array}$ & $\begin{array}{c}\% \text { de } \\
\text { miembros } \\
\text { de la familia } \\
\text { dedicados a } \\
\text { la finca }\end{array}$ \\
\hline 1 & El Triunfo & 5 & 0 & 2 & 1 & 1 & 1 & 0 & 5 & $100,0 \%$ \\
\hline 2 & Las Camelias & 3 & 1 & 0 & 0 & 1 & 1 & 0 & 2 & $66,7 \%$ \\
\hline 3 & La Loma & 7 & 0 & 4 & 1 & 1 & 1 & 0 & 7 & $100,0 \%$ \\
\hline 4 & El Triángulo & 3 & 0 & 1 & 0 & 0 & 0 & 2 & 3 & $100,0 \%$ \\
\hline 5 & El Gualanday & 5 & 1 & 0 & 2 & 0 & 1 & 1 & 4 & $80,0 \%$ \\
\hline 6 & Los Bojos & 5 & 0 & 0 & 1 & 2 & 0 & 2 & 5 & $100,0 \%$ \\
\hline 7 & $\begin{array}{l}\text { El Pomo/ } \\
\text { El Naranjo }\end{array}$ & 7 & 0 & 5 & 0 & 1 & 1 & 0 & 7 & $100,0 \%$ \\
\hline 8 & $\begin{array}{l}\text { Brisas de La } \\
\text { Argentina }\end{array}$ & 4 & 2 & 0 & 2 & 0 & 0 & 0 & 4 & $100,0 \%$ \\
\hline 9 & Los Nogales & 5 & 1 & 2 & 1 & 1 & 0 & 0 & 5 & $100,0 \%$ \\
\hline 10 & La Fortuna & 7 & 0 & 2 & 2 & 1 & 0 & 2 & 7 & $100,0 \%$ \\
\hline 11 & El Crucero & 5 & 1 & 2 & 0 & 0 & 1 & 1 & 5 & $100,0 \%$ \\
\hline 12 & El Yarumo & 4 & 0 & 2 & 1 & 0 & 1 & 0 & 4 & $100,0 \%$ \\
\hline 13 & El Descanso & 4 & 0 & 0 & 0 & 2 & 0 & 2 & 4 & $100,0 \%$ \\
\hline 14 & La Morra & 5 & 2 & 1 & 1 & 1 & 0 & 0 & 3 & $60,0 \%$ \\
\hline 15 & Las Brisas & 5 & 2 & 1 & 0 & 1 & 1 & 0 & 3 & $60,0 \%$ \\
\hline
\end{tabular}


(viene)

\begin{tabular}{|c|c|c|c|c|c|c|c|c|c|c|}
\hline No & $\begin{array}{l}\text { Nombre de la } \\
\text { finca }\end{array}$ & $\begin{array}{c}\text { Total } \\
\text { miembros } \\
\text { de la } \\
\text { familia } \\
\text { que viven } \\
\text { en la finca }\end{array}$ & $\begin{array}{l}\text { Miembros } \\
\text { de la } \\
\text { familia } \\
\text { menores } \\
\text { de } 10 \text { años }\end{array}$ & $\begin{array}{c}\text { Miembros } \\
\text { de la } \\
\text { familia } \\
\text { entre } 10- \\
20 \text { años }\end{array}$ & $\begin{array}{l}\text { Miembros } \\
\text { de la } \\
\text { familia } \\
\text { entre } 20 \text { - } \\
30 \text { años }\end{array}$ & $\begin{array}{l}\text { Miembros } \\
\text { de la } \\
\text { familia } \\
\text { entre } 30- \\
40 \text { años }\end{array}$ & $\begin{array}{l}\text { Miembros } \\
\text { de la } \\
\text { familia } \\
\text { entre } 40- \\
50 \text { años }\end{array}$ & $\begin{array}{c}\text { Miembros } \\
\text { de la } \\
\text { familia } \\
\text { mayores } \\
\text { de } 50 \text { años }\end{array}$ & $\begin{array}{c}\text { No } \\
\text { miembros } \\
\text { dedicados } \\
\text { a la finca }\end{array}$ & $\begin{array}{c}\% \text { de } \\
\text { miembros } \\
\text { de la familia } \\
\text { dedicados a } \\
\text { la finca }\end{array}$ \\
\hline 16 & La Loma & 5 & 1 & 2 & 0 & 0 & 2 & 0 & 4 & $80,0 \%$ \\
\hline 18 & El Descanso & 3 & 0 & 0 & 1 & 0 & 0 & 2 & 3 & $100,0 \%$ \\
\hline 19 & El Guayabo & 5 & 3 & 0 & 2 & 0 & 0 & 0 & 2 & $40,0 \%$ \\
\hline 20 & Llano Grande & 5 & 0 & 3 & 0 & 2 & 0 & 0 & 5 & $100,0 \%$ \\
\hline 21 & El Pino & 4 & 0 & 0 & 1 & 1 & 0 & 2 & 3 & $75,0 \%$ \\
\hline 22 & La Fortuna & 5 & 0 & 1 & 2 & 0 & 0 & 2 & 5 & $100,0 \%$ \\
\hline 24 & Villa Losada & 6 & 1 & 2 & 1 & 0 & 2 & 0 & 6 & $100,0 \%$ \\
\hline 25 & El Yarumal & 4 & 2 & 0 & 2 & 0 & 0 & 0 & 2 & $50,0 \%$ \\
\hline 26 & El Futuro & 4 & 2 & 0 & 2 & 0 & 0 & 0 & 2 & $50,0 \%$ \\
\hline 27 & El Esfuerzo & 4 & 1 & 1 & 0 & 2 & 0 & 0 & 3 & $75,0 \%$ \\
\hline \multicolumn{2}{|r|}{ Promedio } & 5 & 1 & 1 & 1 & 1 & 0 & 1 & 4 & $86,5 \%$ \\
\hline
\end{tabular}

Nota. Elaboración propia

\section{Participación por género}

$\mathrm{Al}$ analizar la manera como se toman las decisiones y se realiza el trabajo, se determina que, en $85 \%$ de los casos, las mujeres y los hombres adultos comparten la responsabilidad en la decisión, el trabajo y el apoyo en las actividades de la finca; $7 \%$ de los hijos adultos toma decisiones, $44 \%$ de los hijos apoya el trabajo de las fincas y $78 \%$ apoya tales labores (tabla 5).

\section{Mano de obra}

Analizando la situación de contratación de mano de obra para adelantar las labores propias de los sistemas de finca estudiados, se obtiene que 8 (30\%) de los 27 sistemas se han visto en la necesidad de pagar mano de obra externa, sobre todo para colaborar en el cultivo del café en las épocas de cosecha. En cambio, en la mayoría de fincas (70\%), solo se emplea la mano de obra familiar (tabla 6).

\section{Criterios de innovación, hibridación o tradición tecnológica}

Se analiza la manera como se configuran las operaciones productivas a nivel de cada sistema de finca tomando como referencia cinco actividades productivas: manejo de suelos, fertilización, tipo de semilla empleada, manejo de arvenses, manejo de plagas y enfermedades (tabla 7).

Tabla 5

Participación por género

\begin{tabular}{|c|c|c|c|c|c|c|c|c|c|}
\hline \multirow{2}{*}{ Ámbito } & \multicolumn{3}{|c|}{ Mujer } & \multicolumn{3}{|c|}{ Hombre } & \multicolumn{3}{|c|}{ Hijos } \\
\hline & Decide & Trabaja & Apoya & Decide & Trabaja & Apoya & Decide & Trabaja & Apoya \\
\hline $\begin{array}{l}\text { Actividades de la finca referidas a: pro- } \\
\text { ducción mercado, producción autocon- } \\
\text { sumo, labores agropecuarias, provisión } \\
\text { de agua y leña, mantenimiento hogar, } \\
\text { ingresos y gastos, asistencia hijos-as, par- } \\
\text { ticipación comunitaria y educación }\end{array}$ & 27 & 27 & 27 & 23 & 23 & 25 & 2 & 12 & 21 \\
\hline
\end{tabular}


Tabla 6

Mano de obra

\begin{tabular}{|c|c|c|c|}
\hline \multirow{2}{*}{$\mathrm{N}^{\circ}$} & \multirow{2}{*}{$\begin{array}{l}\text { Nombre } \\
\text { de la finca }\end{array}$} & \multicolumn{2}{|c|}{ Contrata mano de obra } \\
\hline & & Sí & No \\
\hline 1 & El Triunfo & $\mathrm{x}$ & \\
\hline 2 & Las Camelias & $\mathrm{x}$ & \\
\hline 3 & La Loma & & $\mathrm{x}$ \\
\hline 4 & El Triángulo & & $\mathrm{x}$ \\
\hline 5 & El Gualanday & $\mathrm{x}$ & \\
\hline 6 & Los Bojos & $\mathrm{x}$ & \\
\hline 7 & El Pomo/El Naranjo & $\mathrm{x}$ & \\
\hline 8 & Brisas de La Argentina & $\mathrm{x}$ & \\
\hline 9 & Los Nogales & & $\mathrm{x}$ \\
\hline 10 & La Fortuna & & $\mathrm{x}$ \\
\hline 11 & El Crucero & & $\mathrm{x}$ \\
\hline 12 & El Yarumo & & $\mathrm{x}$ \\
\hline 13 & El Descanso & & $\mathrm{x}$ \\
\hline 14 & La Morra & & $\mathrm{x}$ \\
\hline 15 & Las Brisas & & $\mathrm{x}$ \\
\hline 16 & La Loma & & $\mathrm{x}$ \\
\hline 17 & Los Olivos & $\mathrm{x}$ & \\
\hline 18 & El Descanso & & $\mathrm{x}$ \\
\hline 19 & El Guayabo & & $\mathrm{x}$ \\
\hline 20 & Llano Grande & & $\mathrm{x}$ \\
\hline 21 & El Pino & & $\mathrm{x}$ \\
\hline 22 & La Fortuna & $\mathrm{x}$ & \\
\hline 23 & La Ceiba & & $\mathrm{x}$ \\
\hline 24 & Villa Losada & & $\mathrm{x}$ \\
\hline 25 & El Yarumal & & $\mathrm{x}$ \\
\hline 26 & El Futuro & & $\mathrm{x}$ \\
\hline 27 & El Esfuerzo & & $\mathrm{x}$ \\
\hline Tota & & 8 & 19 \\
\hline
\end{tabular}

Nota. Elaboración propia

Tabla 7

Sistemas de producción

\begin{tabular}{lccccc}
\hline & $\begin{array}{c}\text { Manejo } \\
\text { de suelos }\end{array}$ & $\begin{array}{c}\text { Tipo } \\
\text { de fertilización }\end{array}$ & $\begin{array}{c}\text { Origen } \\
\text { de la semilla }\end{array}$ & $\begin{array}{c}\text { Manejo } \\
\text { de arvenses }\end{array}$ & $\begin{array}{c}\text { Manejo de plagas } \\
\text { y enfermedades }\end{array}$ \\
\hline Tradicional & 0 & 0 & 0 & 0 & 0 \\
Hibridación & 27 & 27 & 27 & 27 & 27 \\
Innovación & 0 & 0 & 0 & 0 & 0 \\
\hline
\end{tabular}

Para el caso de este estudio, se acogieron las distinciones de innovación (técnicas derivadas del proceso de tecnificación impulsado por profesionales e instituciones agrarias), tradición (técnicas derivadas del conocimiento y las prácticas ancestrales tradicionales de los agricultores) e hibridación (combinación de técnicas innovadoras y tradicionales), con el fin de analizar la manera como se configuran las operaciones productivas a nivel de cada sistema de finca.

En $100 \%$ de los sistemas estudiados, las actividades referenciadas se hacen de manera híbrida, haciendo uso de la mecanización y fertilizantes edáficos para el caso de manejo de suelos, intercalando químicos (clorpiritos, cyproconazole, glifosato, propital, foliares, cipermetrina, lorsban, compuestos, roundup, agrimins, producción, urea, KCL y DAP, esencialmente), con orgánicos (cereza, cacota de café, aprobados para el sello FLO) en la fertilización y el manejo de arvenses, así como el de plagas y enfermedades. En el caso de las semillas, utilizan tanto las de su propia cosecha, como las recomendadas y certificadas (en el caso del café principalmente).

\section{Representaciones sociales vinculadas al uso de la tierra}

Se tienen en cuenta cuatro criterios de relación con la tierra, dos referidos a relaciones de explotación y dos referidos a relaciones de respeto, ritual o sagrada con la tierra. En los sistemas de finca evaluados predomina una relación de explotación con conservación funcioimportante cuidarla con fines productivos.

El 33\% de las agricultoras incluidas en el estudio establecen una relación de respeto por la tierra que se manifiesta en sus sistemas tradicionales con protección permanente del suelo, preservación de sus semillas y no uso de medidas agresivas como el uso indiscriminado de agrotóxicos; también manifiestan cuidar de la flora y la fauna silvestres como medio protector (tabla 8). nal de la tierra (67\%), cuyas agricultoras consideran

Nota. Elaboración propia 
Tabla 8

Relación con la tierra

\begin{tabular}{|c|c|c|c|c|c|}
\hline $\mathrm{N}^{\circ}$ & $\begin{array}{l}\text { Nombre } \\
\text { de la finca }\end{array}$ & $\begin{array}{c}\text { Máxima } \\
\text { explotación }\end{array}$ & $\begin{array}{c}\text { Explotación } \\
\text { con conservación } \\
\text { funcional }\end{array}$ & $\begin{array}{l}\text { Respeto, } \\
\text { uso protector }\end{array}$ & $\begin{array}{l}\text { Relación } \\
\text { sagrada }\end{array}$ \\
\hline 1 & El Triunfo & & 1 & & \\
\hline 2 & Las Camelias & 1 & & & \\
\hline 3 & La Loma & 1 & & & \\
\hline 4 & El Triángulo & & 1 & & \\
\hline 5 & El Gualanday & & 1 & & \\
\hline 6 & Los Bojos & & 1 & & \\
\hline 7 & El Pomo/El Naranjo & 1 & & & \\
\hline 8 & Brisas de La Argentina & 1 & & & \\
\hline 9 & Los Nogales & & 1 & & \\
\hline 10 & La Fortuna & 1 & & & \\
\hline 11 & El Crucero & & 1 & & \\
\hline 12 & El Yarumo & & 1 & & \\
\hline 13 & El Descanso & 1 & & & \\
\hline 14 & La Morra & & 1 & & \\
\hline 15 & Las Brisas & & 1 & & \\
\hline 16 & La Loma & & 1 & & \\
\hline 17 & Los Olivos & & 1 & & \\
\hline 18 & El Descanso & & 1 & & \\
\hline 19 & El Guayabo & 1 & & & \\
\hline 20 & Llano Grande & & 1 & & \\
\hline 21 & El Pino & & 1 & & \\
\hline 22 & La Fortuna & & 1 & & \\
\hline 23 & La Ceiba & & 1 & & \\
\hline 24 & Villa Losada & & 1 & & \\
\hline 25 & El Yarumal & 1 & & & \\
\hline 26 & El Futuro & 1 & & & \\
\hline \multirow[t]{2}{*}{27} & El Esfuerzo & & 1 & & \\
\hline & Total & 9 & 18 & 0 & $\mathbf{0}$ \\
\hline
\end{tabular}

Nota. Elaboración propia

\section{Autosuficiencia alimentaria}

Hasta siete alimentos son producidos y consumidos por una parte, y comercializada otra de manera permanente durante al menos ocho meses del año, configurándose en este sentido buena parte de la seguridad alimentaria de las familias (figura 1).

Para el caso de la comunidad en estudio, la producción de alimentos tradicionalmente propios, especialmente maíz, plátano y yuca, por un lado, y huevos y pescado, por el otro, genera la base de una autosuficiencia que libera a las agricultoras de la dependencia del mercado de alimentos.
La autosuficiencia alimentaria es reflejo de la multifuncionalidad, teniendo como soporte comercial un producto competitivo como el café. En los sistemas de finca estudiados se adelantan otras actividades productivas que permiten sobrellevar los costos y gastos propios de la empresa familiar durante las épocas en las que no hay cosecha de café, ya que además de facilitar productos que se consumen directamente, aportan un excedente que se comercializa en los diferentes puntos de mercado a los que se tiene acceso, vale decir, en la misma finca, en la carretera, en el centro poblado o en la plaza de mercado local. En algunas ocasiones, acuden hasta la plaza de mercado regional y hasta aprove- 
chan encuentros comerciales (ferias) para ofertar sus productos, con el problema de la escasa capacidad de acopio de volúmenes comerciales, pues la productividad y la calidad no son las esperadas.

Los productos obedecen a la vocación, tanto de las familias como de las zonas en las que se ubican y a las características del entorno (vale decir clima, relieve), y también están condicionados a la capacidad económica de las familias, que se ven abocadas a emplear los recursos del crédito para solventar sus necesidades.

Es importante agregar que, ante la falta de asistencia técnica directa y permanente, las familias acuden a los técnicos de Cadefihuila o el Comité de Cafeteros para que asistan esos cultivos, con lo que favorecen el híbrido entre la técnica y el trabajo tradicional.

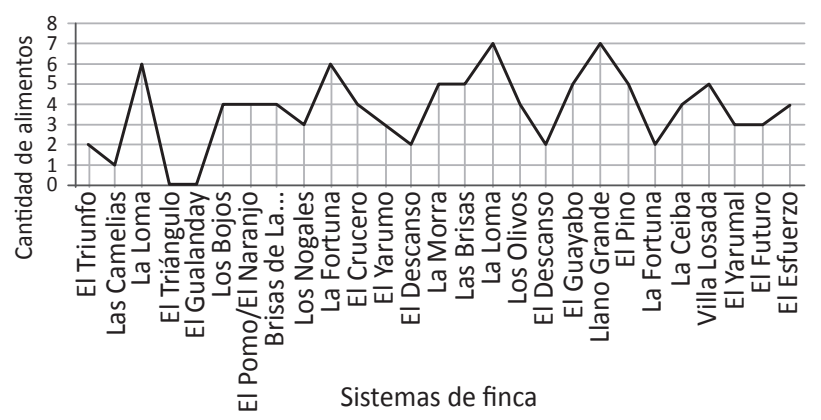

Figura 1. Autosuficiencia alimentaria. Elaboración propia

\section{Actividades productivas de los sistemas de finca}

La figura 2 identifica los diversos productos que se obtienen en los sistemas de finca, los cuales fueron agrupados en diez categorías (procesados para venta, especies combustible, especies productoras de semillas propias, especies artesanales, ornamental-medicinal, forrajeras, maderables, forestales, alimenticias y especies para mercado). La producción de alimento humano y los productos para el mercado (el café producido es vendido en su totalidad a Cadefihuila Ltda., Occicafe ${ }^{3}$ o a comerciantes de La Plata o de La Argentina ${ }^{4}$ ). Los otros cultivos se utilizan para el autoconsumo, entre 40 y $45 \%$, con excedentes comercializables entre 55 y $60 \%$

\footnotetext{
3 Empresa del occidente del Huila dedicada a la comercialización de café.

4 Municipio situado al suroccidente del departamento del Huila, en límites con La Plata.
}

en la vereda o en La Plata o La Argentina, a comerciantes mayoristas o minoristas. Son predominantes entre las unidades familiares, seguidos de la producción de semillas criollas para sus propios arreglos de cultivo diversificado, evidenciándose la interrelación entre los arreglos de policultivos tradicionales, y la producción de semillas criollas y las especies de protección.

La producción de alimento para animales, tanto pastos como forrajes, granos y subproductos, se emplean fundamentalmente en la alimentación de aves de corral, las cuales son criadas en el área de residencia de las familias. La totalidad de los sistemas de finca son generadores de productos para el mercado, destacándose alimentos de pancoger (especialmente plátano, arracacha, yuca y maíz), y cultivos comerciales de café como los principales renglones generadores de ingresos económicos 5 . Solamente un sistema de finca explota el recurso maderable, los demás cuentan con el recurso pero prefieren dejarlo para protección.

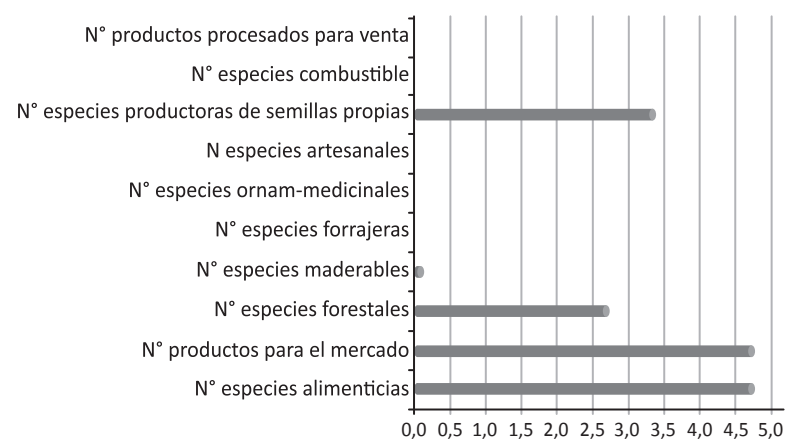

Figura 2. Actividades productivas. Elaboración propia

\section{Conformación del ingreso familiar}

Los sistemas de finca estudiados no llevan contabilidad de sus ingresos y egresos, lo cual se configura en una característica de este tipo de explotaciones y a su vez dificulta el cálculo cierto del nivel de excedentes económicos. El ingreso familiar está conformado por la venta directa de sus cultivos (agrícolas y pecuarios); venden $100 \%$ de la producción de café (verde o seco de trilla), la producción de los cultivos de pancoger y los huevos se vende entre 55 y $60 \%$ y $90 \%$ del pescado lo comercializan. Muy pocos venden su mano de obra a

\footnotetext{
5 Las agricultoras, desafortunadamente, no llevan contabilidad sobre su producción, a duras penas se pudo saber el ingreso por café, gracias al apoyo de los técnicos de Cadefihuila Ltda.
} 
otras fincas de la región. Aunque todas manifestaron utilizar el crédito tanto de instituciones reconocidas (Banco Agrario, Cadefihuila Ltda., Fundación Mundo Mujer, Davivienda, Contactar, Cooperativa Utrahuilca, Banco de Bogotá, Comité de Cafeteros, Banca Mía $)^{6}$, como de familiares y amigos, no estimaron los montos que manejan.

El egreso proviene principalmente de la satisfacción de sus necesidades (salud, alimentación, vivienda, educación, comunicación, participación y ocio, entre otras); muy pocas contratan jornales y no reco- nocen claramente el costo o el gasto por insumos y materiales.

\section{Conservación del suelo, la biodiversidad y la agrobiodiversidad}

En promedio, 78\% de las áreas de los sistemas de finca estudiados se dedica a la producción (café y pancoger), el resto (22\%) se mantiene silvestre en rastrojos y forestales. Estos últimos son explotados por un sistema de finca (tabla 9).

Tabla 9

Uso del suelo

\begin{tabular}{|c|c|c|c|c|c|c|}
\hline $\mathrm{N}^{\circ}$ & $\begin{array}{l}\text { Nombre } \\
\text { de la finca }\end{array}$ & $\begin{array}{c}\text { Área total } \\
\text { (ha) }\end{array}$ & $\begin{array}{c}\text { Área en } \\
\text { producción } \\
\text { total (ha) }\end{array}$ & $\%$ del área total & $\begin{array}{c}\text { Área en } \\
\text { conservación } \\
\text { natural (ha) }\end{array}$ & $\%$ del área total \\
\hline 1 & El Triunfo & 5,00 & 4,25 & $85,0 \%$ & 0,75 & $15,0 \%$ \\
\hline 2 & Las Camelias & 3,00 & 3,00 & $100,0 \%$ & & $0,0 \%$ \\
\hline 3 & La Loma & 0,50 & 0,50 & $100,0 \%$ & & $0,0 \%$ \\
\hline 4 & El Triángulo & 3,00 & 1,50 & $50,0 \%$ & 1,50 & $50,0 \%$ \\
\hline 5 & El Gualanday & 2,00 & 1,50 & $75,0 \%$ & 0,50 & $25,0 \%$ \\
\hline 6 & Los Bojos & 4,00 & 3,00 & $75,0 \%$ & 1,00 & $25,0 \%$ \\
\hline 7 & El Pomo/El Naranjo & 3,00 & 3,00 & $100,0 \%$ & & $0,0 \%$ \\
\hline 8 & Brisas de La Argentina & 2,00 & 2,00 & $100,0 \%$ & & $0,0 \%$ \\
\hline 9 & Los Nogales & 2,50 & 2,20 & $88,0 \%$ & 0,30 & $12,0 \%$ \\
\hline 10 & La Fortuna & 4,00 & 4,00 & $100,0 \%$ & & $0,0 \%$ \\
\hline 11 & El Crucero & 5,00 & 2,00 & $40,0 \%$ & 3,00 & $60,0 \%$ \\
\hline 12 & El Yarumo & 3,00 & 2,00 & $66,7 \%$ & 1,00 & $33,3 \%$ \\
\hline 13 & El Descanso & 2,50 & 2,50 & $100,0 \%$ & & $0,0 \%$ \\
\hline 14 & La Morra & 5,00 & 4,75 & $95,0 \%$ & 0,25 & $5,0 \%$ \\
\hline 15 & Las Brisas & 0,75 & 0,50 & $66,7 \%$ & 0,25 & $33,3 \%$ \\
\hline 16 & La Loma & 4,50 & 3,50 & $77,8 \%$ & 1,00 & $22,2 \%$ \\
\hline 17 & Los Olivos & 5,00 & 1,00 & $20,0 \%$ & 4,00 & $80,0 \%$ \\
\hline 18 & El Descanso & 2,00 & 1,50 & $75,0 \%$ & 0,50 & $25,0 \%$ \\
\hline 19 & El Guayabo & 2,00 & 2,00 & $100,0 \%$ & & $0,0 \%$ \\
\hline 20 & Llano Grande & 3,00 & 2,75 & $91,7 \%$ & 0,25 & $8,3 \%$ \\
\hline 21 & El Pino & 5,00 & 3,00 & $60,0 \%$ & 2,00 & $40,0 \%$ \\
\hline 22 & La Fortuna & 5,00 & 2,00 & $40,0 \%$ & 3,00 & $60,0 \%$ \\
\hline 23 & La Ceiba & 3,00 & 2,00 & $66,7 \%$ & 1,00 & $33,3 \%$ \\
\hline 24 & Villa Losada & 8,00 & 3,00 & $37,5 \%$ & 5,00 & $62,5 \%$ \\
\hline 25 & El Yarumal & 0,25 & 0,25 & $100,0 \%$ & & $0,0 \%$ \\
\hline 26 & El Futuro & 0,50 & 0,50 & $100,0 \%$ & & $0,0 \%$ \\
\hline \multirow[t]{2}{*}{27} & El Esfuerzo & 1,10 & 1,00 & $90,9 \%$ & 0,10 & $9,1 \%$ \\
\hline & Promedio & 3,13 & 2,19 & $78,0 \%$ & 0,94 & $22,0 \%$ \\
\hline
\end{tabular}

Nota. Elaboración propia

6 Todas estas instituciones están autorizadas para prestar el servicio de crédito. 
Es interesante observar cómo el área asignada a la producción integra los sistemas agrícolas y pecuarios, con productos que van al autoconsumo o al mercado en los diferentes puntos de comercialización que tienen identificados. Todos los sistemas de finca dedican una parte importante de su extensión a la producción, con áreas que van desde 0,25 ha hasta 8,0 ha.

\section{Conclusiones}

Los resultados alcanzados permiten identificar claramente que la agricultura familiar en el municipio de $\mathrm{La}$ Plata, analizada desde los sistemas de finca manejados por las afiliadas a la asociación de mujeres, se desarrolla a partir de la complementariedad de varios productos, ya sean agrícolas o pecuarios, los cuales suman al ingreso económico de cada familia cuando se comercializan o son determinantes del consumo en el mismo sistema de finca.

Los sistemas de finca en los que se desarrolla la agricultura familiar tienen pequeñas extensiones. El promedio de ellos apenas llega a las 3,13 ha. En esa extensión, dedican $78,0 \%$ a la producción agropecuaria, predominando el café como base económica, pero complementado con la presencia de pastos, fríjol, plátano y banano, arracacha, yuca y maíz, entre otros. También se identifica la importancia que adquieren las zonas de protección, con bosques o rastrojos y algunos animales de corral, especialmente gallinas criollas y pollos, así como peces.

La caracterización de estos sistemas de finca en los que se desarrolla la agricultura familiar comprende:

- Extensiones pequeñas, en promedio 3,13 ha.

- Tenencia lícita de la tierra, el 77,8\% de los propietarios cuenta con documento que avala su tenencia.

- El grado de escolaridad de las agricultoras es bajo, predomina la primaria.

- Solamente se emplea mano de obra particular en épocas de cosecha, de resto se utiliza la mano de obra familiar.

- Utilizan un sistema de producción que mezcla el tradicional con el innovador o técnico.

- Se manifiesta una constante preocupación por la conservación de los suelos y del medio ambiente.

- Identifican un producto comercial, al que consideran su eje económico, y alrededor de él desarrollan otros sistemas productivos de índole agrícola y pe- cuario, cuya cosecha la dividen en el autoconsumo y en la comercialización.

- Utilizan sistemas de crédito que resultan onerosos para su actividad, el mismo hecho de la multifuncionalidad de sus sistemas de finca los hace requerir de varias fuentes de recursos a la vez.

Es importante hacer notar que en el proyecto de la asociación de mujeres se compromete el núcleo familiar, pero la razón fundamental es mantener el relevo generacional y servir de apoyo económico, social y cultural, haciendo más visible el trabajo que realizan las mujeres en la empresa agrícola. Se interactúa con la familia y se inculca en los hijos el valor que tiene la tierra, su riqueza y cómo haciendo un buen uso de ella se puede producir alimentos de calidad, así como se les enseña a compartir, ser solidarios y fortalecer los lazos de amistad entre vecinos. Al inicio de este proyecto organizacional, el jefe del hogar era quien daba las órdenes y realizaba todo lo pertinente a la empresa cafetera; la señora se dedicaba al cuidado de los hijos y labores de hogar, sin permitírsele si quiera dar una opinión. Esto fue cambiando y, hoy en día, la mujer tiene su propio lote de terreno en donde trabaja el núcleo familiar, hijos y esposos, y con esos ingresos colaboran en todos los gastos de la empresa cafetera.

La multifuncionalidad de la agricultura familiar y la asociatividad social y solidaria, en el caso de la asociación:

- Inculca el valor cultural, social y económico de la comunidad.

- Integra a la familia al trabajo en equipo.

- Resalta el trabajo de la mujer como parte fundamental en la sociedad.

- El aporte de la mujer en la empresa cafetera concientiza a los esposos acerca de la importancia del trabajo en equidad de género.

- Conserva la flora y la fauna.

- Fortalece el trabajo interinstitucional (Comité de Cafeteros, sena, Cooperativa de Caficultores).

- Contribuye al bienestar de la familia con una alimentación sana.

- Facilita el mejoramiento económico del núcleo familiar.

- Produce alimentos de calidad que contribuyen a la alimentación de muchas familias del entorno. 


\section{Referencias}

Administración municipal de La Plata-Huila. (2005). Revisión y Ajuste del Plan Básico de Ordenamiento Territorial La Plata-Huila.

Asamblea Departamental del Huila. (2013). Ordenanza N. ${ }^{\circ}$ 017 del 2013. Por la cual se adopta el plan de desarrollo "Huila Competitivo" y se dictan otras disposiciones. Huila: Asamblea Departamental. Disponible en http:// www.huila.gov.co/plan-de-desarrollo-huila-competitivo.html

Acevedo, A. (2014). Contribuciones de la agricultura familiar en Colombia desde el enfoque de la multifuncionalidad. Estudio de caso en la comunidad indígena Lomas de Guaguarco, Coyaima, Tolima. Documento de trabajo. Corporación Universitaria Minuto de Dios.
Alcaldía Municipal La Plata-Huila. (2012). Plan de Desarrollo 2012 - 2015: "Unidos por la vía de la prosperidad”. La Plata: Alcaldía Municipal La Plata-Huila. Disponible en http://laplata-huila.gov.co/apc-aa-files/33353664333038336434336263386561/plan-de-desarrollo-2012-2015_3.pdf

Caballero, C. (2013, 21 de junio). ¿Cuántos campesinos hay? Portafolio.co. Disponible en http://www.portafolio.co/ columnistas/cuantos-campesinos-hay

La producción agropecuaria del Huila se acercó a los \$2 billones en 2013. (2014, 13 de mayo). Diario del Huila. Disponible en http://diariodelhuila.com/economia/laproduccion-agropecuaria-del-huila-se-acerco-a-los\$2-billones-en-2013-cdgint20140503084732181 